\section{Absolute Configuration of Spicamycin, an Antitumor Antibiotic Produced by Streptomyces alanosinicus}

\author{
Teruyuki SaKai ${ }^{*, a}$, Kazutoshi ShINdo ${ }^{a}$, \\ Atsuo Odagawa ${ }^{\mathrm{a}}$, AKashi SuzUKI ${ }^{\mathrm{a}}$, \\ HIROYUKi KaWAI ${ }^{\mathbf{a}}$, KIMIKO KOBAYASHI ${ }^{\mathbf{b}}$, \\ Yotchi Hayakawa ${ }^{c}$, Haruo Seto ${ }^{c}$ \\ and NOBORU ŌTAKE ${ }^{d}$

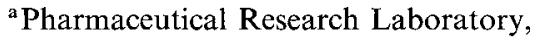 \\ Kirin Brewery Co., Ltd.,
}

3, Miyahara-cho, Takasaki-shi, Gunma 370-12, Japan

${ }^{b}$ The Institute of Physical and Chemical Research (RIKEN), Wako, Saitama 351-01, Japan

'Institute of Molecular and Cellular Biosciences, University of Tokyo,

1-1-1 Yayoi, Bunkyo-ku, Tokyo 113, Japan

${ }^{d}$ Department of Biosciences, Teikyo University,

1-1-1, Toyosatodai, Utsunomiya-shi, Tochigi 320, Japan

(Received for publication December 7, 1994)

Spicamycin (1) is a mixture of several related components that differ only in the nature of their fatty acid moieties. The mixture is produced by Streptomyces alanosinicus $879-\mathrm{MT}_{3}$, and was isolated as a differentiation inducer of mouse myeloid leukemia cells (M1) and human promyelocytic leukemia cells (HL-60) ${ }^{1,2)}$. It also showed antitumor activity against P388 leukemia in mice.

By preparation of several semi-synthetic spicamycin analogues which differed in the length of the fatty acid moiety, we found that the dodecanoyl analogue showed an excellent activity against human gastric cancer SC-9 in the human xenograft model ${ }^{3)}$.

Since the relative configuration at C- $6^{\prime}$ and the absolute configuration of their interesting compounds remained unknown, we have attempted to solve these problems by chemical degradation, X-ray analysis and the TACu method $^{4)}$. The relative configuration of the spicamycin amino nucleoside (SAN, 2) ${ }^{3)}$ obtained by treatment of 1 with $10 \% \mathrm{HCl}$ in methanol was determined by means of $\mathrm{X}$-ray analysis, and the absolute configurations of $\mathrm{C}-3^{\prime}$ and $\mathrm{C}-4^{\prime}$ of the amino sugar $(3)^{2)}$ prepared by treatment of 2 with $1 \mathrm{~N} \mathrm{HCl}$ under reflux were determined by the TACu method ${ }^{4)}$.

Colorless crystals of $\mathbf{2}$ were grown in methanol - water solution. A small fragment of approximate dimensions $0.43 \times 0.18 \times 0.02 \mathrm{~mm}$ was mounted on an Enraf-Nonius CAD4R diffractometer and the unit cell dimensions and intensity data were obtained using $\mathrm{Cu} K_{\alpha}$ radiation monochromated by a graphite plate, in the $\omega$-scan mode. The crystal data were: spicamycin amino nucleoside water methanol solvate, $\mathrm{C}_{12} \mathrm{H}_{18} \mathrm{~N}_{6} \mathrm{O}_{5} \cdot 2 \mathrm{H}_{2} \mathrm{O}$. $1.5 \mathrm{CH}_{3} \mathrm{OH}, \mathrm{Fw}=410.42$. Monoclinic, space group $C 2$, $a=18.957(2), b=7.239(1), c=13.327(2) \AA, \beta=$ $104.39(1)^{\circ}, U=1771(4) \AA^{3} . Z=4, D_{\text {calc }}=1.539 \mathrm{~g} \mathrm{~cm}^{-3}$, $F(000)=876, \mu\left(\mathrm{CuK}_{\alpha}\right)=10.5 \mathrm{~cm}^{-1}$.

Three standard reflections showed no significant deterioration during the couse of $\mathrm{X}$-irradiation. Within the range of $4^{\circ} \leq 20 \leq 136^{\circ}, 1721$ reflections were measured and 1645 unique reflections obtained with $\left|F_{0}\right|>4 \sigma\left(\left|F_{0}\right|\right)$. The structure was solved by the direct method using the MULTAN7 ${ }^{5}$ ) procedure and refined by the method of least-squares with block-diagonal approximations.

The $\mathrm{H}$ atom positions except those of the methanol solvate were located from a difference Fourier synthesis. All non-hydrogen atoms were refined anisotropically and $\mathrm{H}$ atoms isotropically. The final $\mathrm{R}$ and $\mathrm{R} w$ values were 0.054 and 0.057 , respectively. The source of scattering factor data was given by the International Tables for X-ray Crystallography $(1974)^{6}$. Crystallographic calculations were performed on a FACOM M-1800 computer using UNICS-III program system ${ }^{7}$. In the crystals, the molecules are linked by an intermolecular hydrogen bond $\mathrm{O} 6-\mathrm{H}^{\prime} \cdots \mathrm{N} 4^{\prime i}, 2.836(6) \AA, 176(8)^{\circ}$ where $\mathrm{i}$ is

Fig. 1. Chemical degradation of spicamycin (1).
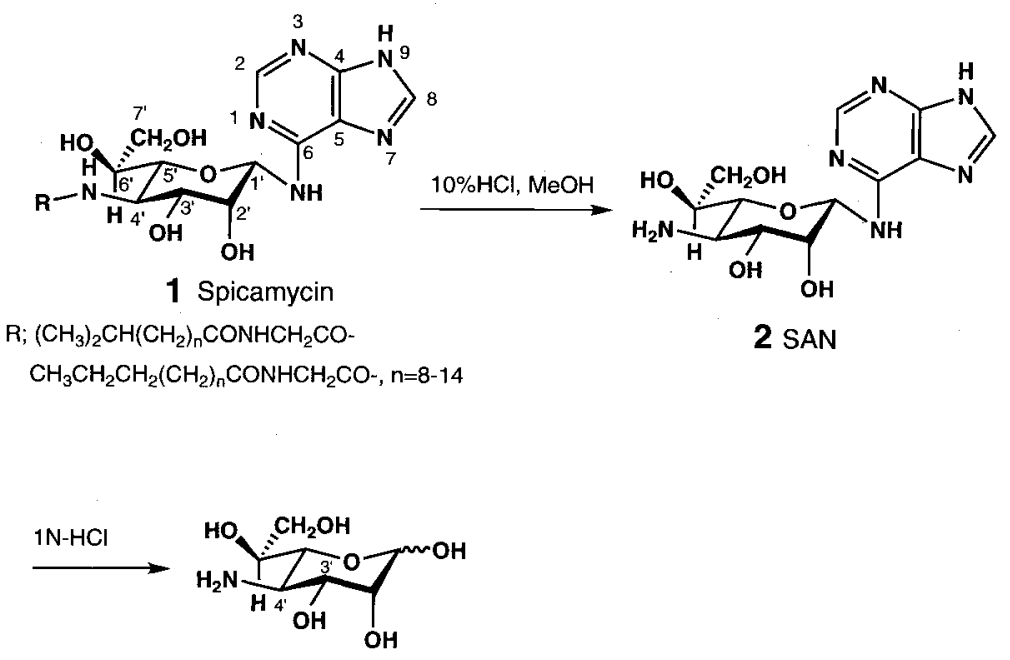
Fig. 2. X-ray crystal structure of SAN (2).

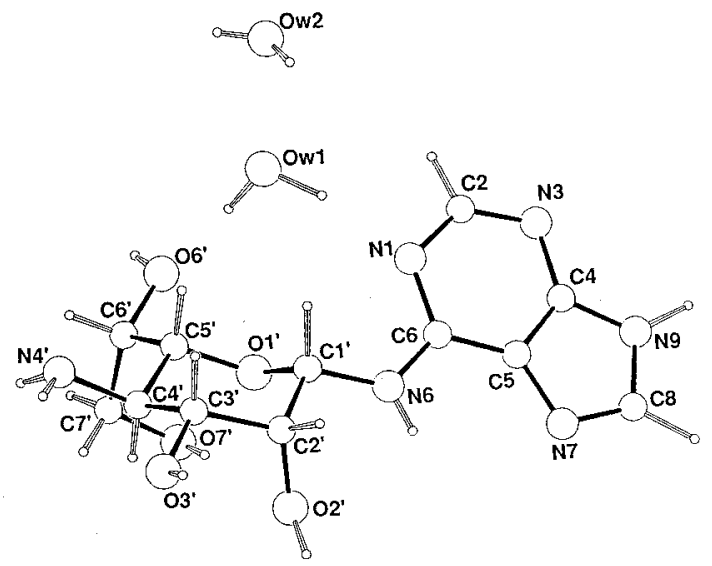

\# All atoms except hydrogens were numbered in every element for convenience to explain the presence of intermolecular and intramolecular hydrogen bonding and the absolute configuration of the amino sugar moiety.

at $3 / 2-x, 1 / 2+y,-z$. Two water molecules are linked by hydrogen bonds, Ow1 ‥H-Ow2, 2.742(7) $\AA, 129(9)^{\circ}$ and $\mathrm{Ow} 2-\mathrm{H} \cdots \mathrm{Ow} 2^{\mathrm{ii}}, 2.89(1) \AA, 138(7)^{\circ}$ where ii is at $1-x, y,-z$. The molecules of 2 and the two water molecules are also held together by a network of hydrogen

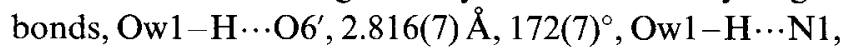
$2.829(5) \AA, \quad 158(7)^{\circ}$ and $\mathrm{Ow} 2 \cdots \mathrm{H}-\mathrm{O} 3^{\prime \text { iii }}, 2.756(8) \AA$, $144(6)^{\circ}$ where iii is at $-1 / 2+x, 1 / 2+y, z$.

The absolute configurations at $\mathrm{C}-3^{\prime}$ and $\mathrm{C}-4^{\prime}$ of the amino sugar (3) were determined by the TACu method ${ }^{4}$ : 3 showed negative contribution $\left[[\alpha]_{436}^{25}-22.5^{\circ}(c 0.04\right.$, $\mathrm{H}_{2} \mathrm{O}$ ), $\left.\Delta[\mathrm{M}]_{\text {TACu }}-788^{\circ}\right]$. This result shows that the absolute configurations at $\mathrm{C}-3^{\prime}$ and $\mathrm{C}-4^{\prime}$ are $R$ and $R$, respectively.
Therefore, the structure of SAN (2) was determined to be 6-(4-amino-4-deoxy-L-glycero- $\beta$-L-manno-heptopyranosylamino)- $9 H$-purine.

\section{References}

1) Hayakawa, Y.; M. Nakagawa, H. KawaI, K. Tanabe, H. Nakayama, A. Shimazu, H. Seto \& N. Ōtake: Studies on the differentiation inducers of myeloid leukemic cells III. Spicamycin, a new inducer of differentiation of HL-60 human promyelocytic leukemia cells. J. Antibiotics 36: 934 937, 1983

2) Hayakawa, Y; M. Nakagawa, H. Kawai, K. Tanabe, H. Nakayama, A. Shimazu, H. Seto \& N. Ōtake: Spicamycin, a new differentiation inducer of mouse myeloid leukemia cells (M1) and human promyelocytic leukemia cells (HL-60). Agric. Biol. Chem. 49: 2685 2691, 1985

3) Kamishohara, M.; H. Kawai, A. Odagawa, T. Isoe, J. Mochizuki, T. UChida, Y. Hayakawa, H. Seto, T. Tsuruo \& N. ŌTAKE: Structure-antitumor activity relationship of semi-synthetic spicamycin analogues. J. Antibiotics 46: 1439 1446, 1993

4) Umezawa, S.; T. Tsuchiya \& K. Tatsuta: Studies of aminosugars. XI. Configurational studies of aminosugar glycosides and aminocyclitols by a copper complex method. Bull. Chem. Soc. Jpn. 39: 1235 1243, 1966

5) Main, P.; S. E. Hull, L. Lessinger, G. Germain, J.-P. DeClerce \& M. M. WoOlfSon: MULTAN78, A Program for the Automatic Solution of Crystal Structures from X-ray Diffraction Data. Univ. of York, England, and Louvain, Belgium, 1978

6) International Tables for X-ray Crystallography. Vol. IV. Birmingham, Kynoch Press, 1974

7) Sakurai, T. \& K. Kobayashi: On the universal crystallographic computation program system (5). UNICS III system. Rep. Inst. Phys. Chem. Res. 55: 69 77, 1979 